We hope we have said enough to give readers on this side of the Atlantic some idea of the thoroughness with which Dr. Resnick has gone into the subject and the admirable way in which he has completed his investigations and marshalled his facts.

The book is written in a very pleasant style, paper, print and illustrations are all good, and we have thoroughly enjoyed reading it.

A Handbook of Ophthalmology. By Humphrey NeAme and F. A. Williamson-Noble. Fourth Edition, 8vo., pp. XVI and 320. London: J. and A. Churchill. 1942. Price 18/..

The fact that a fourth edition of this handbook has been issued within 15 years of the first issue is proof that it meets the needs of the students and general practitioners for whom it has been written. - In our opinion it is one of the best of the shorter text-books on ophthalmology in our language. It is written in an easy style, rarities are kept in the background and nothing of importance to the student has been omitted. The illustrations, many of them in colour, are excellent; and our only criticism is that we think that students, in particular, would have been glad if a coloured illustration of retinal detachment had been added.

The fourth edition has been brought up to date by inclusion of an account of sulphanilamide in the treatment of ophthalmia neonatorum and purulent conjunctivitis of adults, and also with regard to the influence of allergy in phlyctenular lesions and uveitis. Affections of the retina of vascular or toxic origin are now classed under retinopathy rather than retinitis. New work in the aetiology of glaucoma is also mentioned, while the section on tropical ophthalmology, by Colonel Williamson, has been re-written and that on intra-capsular extraction of cataract enlarged.

A word of praise is due to the very complete index.

\title{
CORRESPONDENCE
}

To the Editors of THE BRitish Journal of Ophthalmology.

DEAR SIRS,- - The paper by Dr. Stutterheim published in this issue would seem to call for some comment by me.

I took particular care in my Middlemore lecture to give Dr. Stutterheim the credit he richly deserves for being the pioneer in kinetic treatment of the eyes, and I have therefore no wish to cross swords with him. It is a pity, however, but perhaps understandable, that a pioneer should deprecate any modification in his methods. But the modifications I described would seem to be justified according to the figures quoted by Dr. Stutterheim, namely, that five lessons 
by our method sufficed in a large proportion of patients ( 89 cures, 15 improvements in 117 cases) to bring about the desired result, whereas he, employing his own method has to see the patients for a quarter of an hour every day for a month. Such a procedure is obviously possible in Johannesburg, or it would not have been carried out in two thousand patients, but it would be extremely difficult in London, and probably impossible in most cases.

Many other points might also be commented upon, e.g., whether the work should be done by an orthoptic trainer, or by an ophthalmic surgeon. My own feeling in favour of the orthoptic trainer seems to have been justified by results, and I do not see how anyone who has satisfied the examiners of the Orthoptic Board, can fail to have acquired enough knowledge of ophthalmic physiology to employ intelligently, the methods we have for increasing convergence power. In my own cases, what we aimed at was the voluntary production of diplopia by convergence, because we found that the patients tended to relapse when they had only been taught how to overcome the diplopia produced by prisms base out.

May I conclude, Sirs, by once again congratulating Dr. Stutterheim on his pioneer work, and by stating that our object was to amplify this and not to stultify it.

Yours faithfully,

F. A. Williamson-Noble.

\section{THE EDUCATION OF AN OPHTHALMIC SURGEON}

\section{To the Editors of The BRitish Journal of Ophthalmology.}

DeAR SIRs, - The Education of an Ophthalmic Surgeon, which involves the whole problem of medical education, including therein the curriculum and qualifying and higher examinations, is too large a subject to be dealt with adequately in a letter. Mr. Gayer Morgan has very ably brought forward some points of fundamental importance; and it is possible that, at a time when reformation and reconstruction of medical practice, as well as of other social affairs, are universally acknowledged to be imperative, more success may perhaps be attained than in the past.

When the D.O.M.S. was instituted twenty or more years ago, I was myself afraid that it might be regarded as sufficient evidence of ability to fulfil all the functions of an "ophthalmic surgeon." I therefore strongly urged the institution of a higher conjoint diploma. Realizing that the designation "ophthalmic surgeon" is a misnomer, and that the ophthalmologist should be a physician as well as a 